\title{
Analysis of Quality of Service on Internet Networks Using the Burst Method
}

\author{
Muhammad Fariz ${ }^{1 *}$, Riza Arifudin ${ }^{2}$ \\ ${ }^{1,2}$ Department of Computer Science, Universitas Negeri Semarang, Indonesia
}

\begin{abstract}
Purpose: The purpose of this research is to make comparisons on the internet network using the application of the Burst method and processed with Quality of Service analysis in which there are parameters of throughput, delay, and jitter. This analysis was carried out because there was a problem with a slow internet network. This happens because there is no configured bandwidth management on the Microtic router and also the unequal distribution of bandwidth when more and more bandwidth users.

Methods: Burst is one of the bandwidth management methods available on the Microtic router. Quality of Service analysis is performed to test the parameters of throughput, delay, and jitter on each of the internet networks. After this test is complete, it shows that the results of using the Burst method as a bandwidth regulator, internet network access can be controlled, and each client gets the bandwidth evenly as needed.

Result: The work result using Burst is more optimal than performance without using Burst. By using Burst the number of packets lost and failed transactions is reduced by more than $70 \%$.

Novelty: This study focuses on the implementation of Burst which is applied to one client 2 and will be compared with client1 without the application of Burst.
\end{abstract}

Keywords: Quality of Service, Burst, Internet Network

Received April 2021 / Revised May 2021 / Accepted May 2021

This work is licensed under a Creative Commons Attribution 4.0 International License.

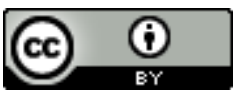

\section{INTRODUCTION}

The rapid development of computer technology is accompanied by network development, in this case the internet network [1]. Along with the increasing number of internet users, traffic on the network is increasingly complex and network management is required [2]. The main cause of underused bandwidth is certainty in network parameters[3]. Quality of Service (QoS) can be said as a term used to define the characteristics of a network service. This is to find out how good the quality is in the service. QoS is designed to help end users be more productive by ensuring that users get reliable performance from applications [2]. Microtic router has a queuing facility that can make bandwidth allocation settings for each user's computer with careful Burst analysis and calculation applications. Burst is a proxy router feature that uses the user's computer to obtain more than the Maximum Information Rate (MIR) bandwidth application within a certain period of time [4]. This technique allows clients to get a bandwidth allocation greater than the maximum bandwidth allocation provided in a certain time interval. This is very beneficial for clients who only use the internet for browsing activities, because browsing speed will increase, even if only for a few seconds. However, this will make the web page loading process faster. In its application, Burst bandwidth can be implemented into a proxy router [5]. Bandwidth management system is the process of setting the right bandwidth for each user on an internet network system that supports the needs of internet service applications. Information technology that is fast today is very influential on human life. This scheme is validated through a simulation, which shows that the proposed traffic management policy outperforms the current traffic management policy [6]. Quality of Service is a method of managing bandwidth that is available and distributed rationally. Quality of Service can be said as a terminology used to define the characteristics of a network service to find out how good the quality is in the service. Quality of Service is designed to help end users be more productive by ensuring that users get reliable performance. It has been found that the method provides an iterative calculation of the desired control variable, the amount of literacy

*Corresponding author.

Email addresses: muhammadfariz@ students.unnes.ac.id (Fariz), rizaarifudin@ mail.unnes. ac.id (Arifudin) DOI: $10.15294 /$ sji.v8i1.29781 
depends on the network structure, the number of available network resources, the number of flows and the requirements for QoS [7]. The research entitled "QoS Based Admission Control Using Multipath Scheduler for IP over Satellite Networks" is an implementation of balancing the bandwidth load and queue length on each link via satellite to meet the optimal QoS level for each type of traffic (Haitham, 2017). This research focuses on how to use Busrt as a method for implementing QoS and also for bandwidth management and then comparing the performance before and after using Burst.

\section{METHODS}

This research was conducted by applying various stages starting from determining the network topology, determining network devices to determining the specifications of the equipment to be used. One of the advantages that need to be considered when choosing a network topology is regarding high data security, it shows that the star topology is the choice for research due to high security [8]. In this study, using a proxy router and two laptops that function as clients. The next step is to configure the network which includes all the network topology devices that have been made, then test the router proxy configuration.

After all the network devices have been strung into a star topology, the next step is to configure the basic network for each client, the goal is that the clients can communicate with each other and also have access to the internet network. On the router, configuration of giving an ip address in the form of an ip address for each client, ip routing in the form of the dhcp server, then setting up the dns server so that all clients can access the internet network. Then after everything is configured correctly, the next step is to do QoS testing using wireshark software which aims to get data before using Burst as one of the methods for QoS analysis [9]. After the data is obtained, the next step is to configure Burst on the proxy and also perform bandwidth management at the same time.

The QoS analysis test is again carried out after Burst is configured, it aims to get new results, and will then be compared with the previous results before using Burst as the QoS method, the network topology can be seen in Figure 1.

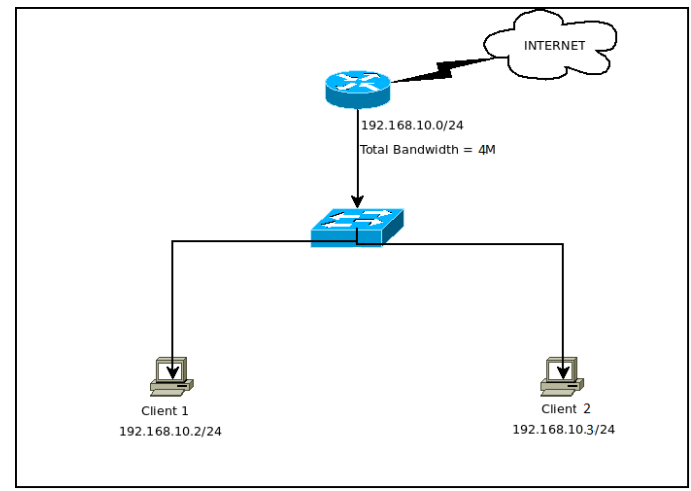

Figure 1. Network topology

\section{RESULT AND DISCUSSION}

When all the network topology components have been designed and configured correctly, then the next stage is testing the entire network topology that has been made. When everything has been confirmed that the router and Burst are properly configured, the next step is to capture packet data with the Wireshark software, when doing this process because only ICMP data packets are analyzed, the data capturing process uses the tcp command in the Wireshrak software so that it only displays ICMP protocol data packets. . This process uses a maximum load of 262144 bytes. The results of this data capture are in the form of throughput, delay, and jitter. From these results, it will be obtained data that is analyzed, namely the comparison between before there is a change in the network system and after there is a change in the network system so that the desired results are obtained which can answer the objectives of this study. Based on the existing topology, the job search of the system is shown in Figure 2. 


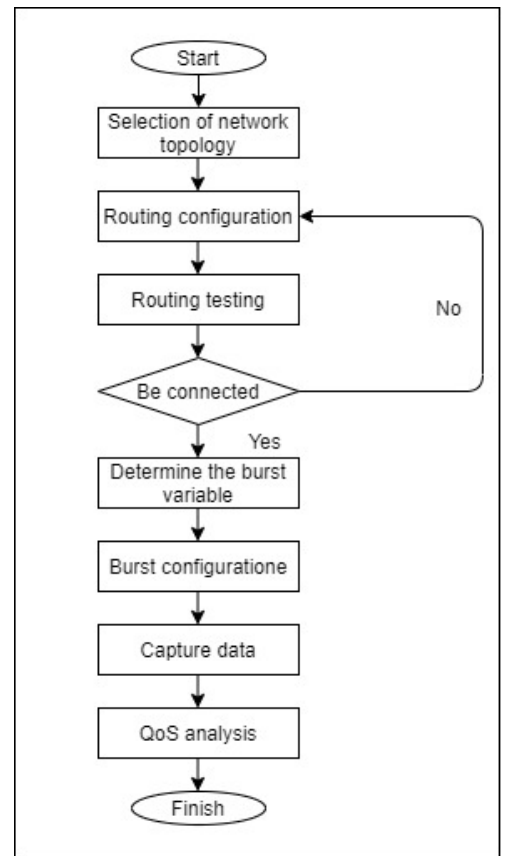

Figure 2. Research process

Before performing the search process, the QoS analysis parameter is the capture of data on the data packet network path using wireshark software, this process is carried out on client 1 without burst and client 2 using Burst, the results of data capture are as in Figure 3.

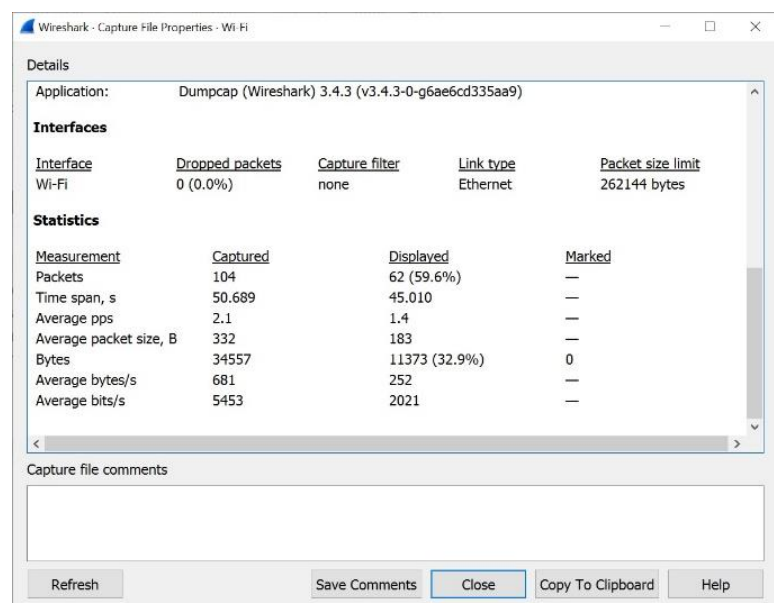

Figure 3. Capture data client 1

The next process is capture data on client 2 as shown in Figure 4. 


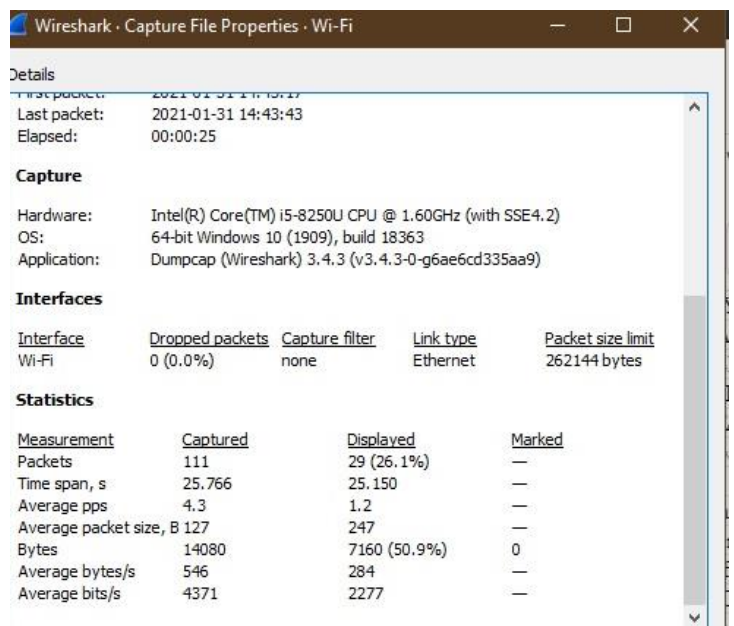

Figure 4. Capture data client 2

This research will conduct several testing of QoS parameters including throughput testing, delay testing, and jitter testing. This research also conducted a scenario that is limiting the bandwidth for each client, namely $5 \mathrm{Mb}$ for client 1 and client 2 . The first test is to find the throughput value with the Equation 1.

$$
\text { Throughput }=\frac{\text { the amount of data sent }}{\text { data transmission time }}
$$

The second test is to find the delay value with the Equation 2.

$$
\text { Delay = Time the package arrives }- \text { The time the packet is sent }
$$

The last test is to find the jitter value with the Equation 3.

$$
\text { Jitter }=\frac{\text { total delay variation }}{\text { total packages received }}
$$

From the results of the calculation of the value of the QoS analysis, the first is the comparison of throughput to client 1 and client1. This calculation uses Equation 1 and the results are as in Figure 5.

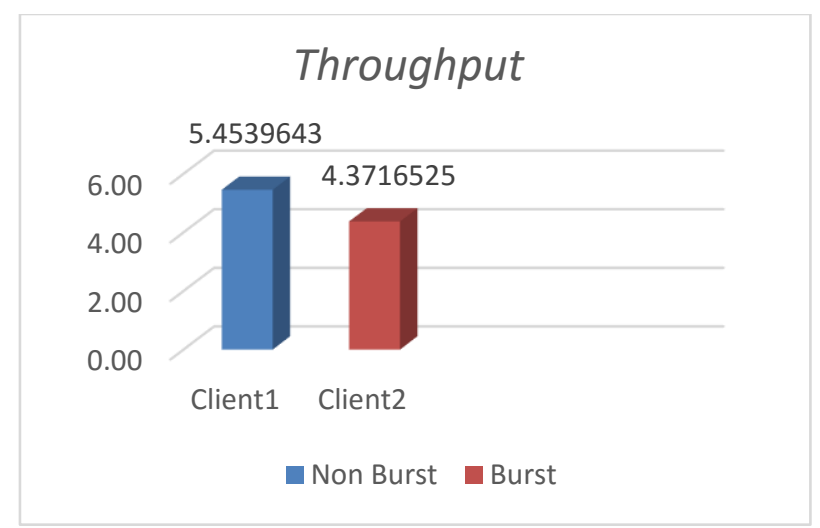

Figure 5. Throughput

Figure 5 shows a decrease in throughput so that concurrency has increased after Burst. The next parameter that is measured is the delay using Equation 2 and the results are as in Figure 6. 


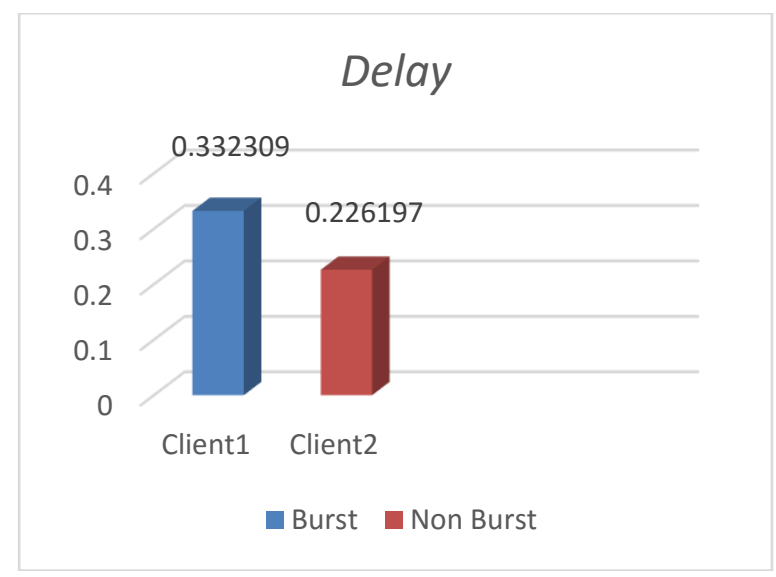

Figure 6. Delay

Delay at a maximum load of 262144 bytes client 2 shows a smaller delay than client 1 with the result of $332309 \mathrm{~s}$ in Figure 6. Next is the calculation of the jitter value using Equation 3 and the results are as in Figure 7.

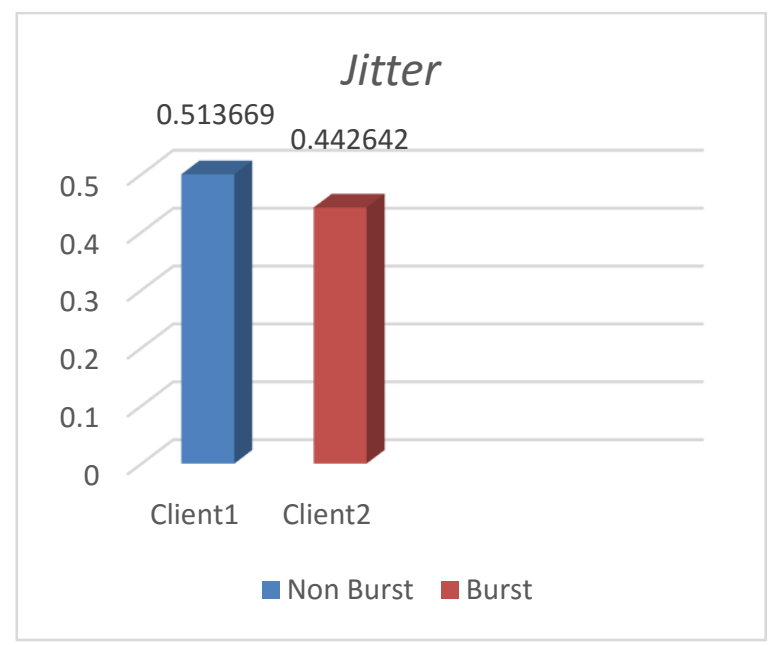

Figure 7. Jitter

\section{CONCLUSION}

From the results of research and discussion related to Quality of Service Analysis on Internet Networks Using the Burst Method. With QoS parameters including throughput, delay, and jitter at maximum load, it can be concluded that sending ICMP data packets at a maximum load of 626144 bytes client 1 produces a larger thoughput, namely 5.4539643 than other routing clients 4.3716525 . Then for delay at a maximum load of 262144 bytes, client 2 delay is smaller than client 1 , namely 0.226197 with the result of client delay 1 0.332309 . Then for the results of jitter at a maximum load of 262144 bytes, client 1 results in a greater jitter of $0.513669 \mathrm{~s}$ than client 2 , namely 0.442646 . From the results of the tests that have been carried out, it is found that Burst can be used as a method that can be used for QoS analysis. Performing bandwidth management on the network can also be done using Burst. The conclusion of this study is that using Burst as one of the QoS methods is very suitable to increase the validity of data transmission even though it has to sacrifice bandwidth limits.

\section{REFERENCES}

[1] M. Buragohain and S. Nandi, "Quality of Service provisioning in Named Data Networking via PIT Entry Reservation and PIT Replacement Policy," Comput. Commun., vol. 155, no. June 2019, pp. 166-183, 2020.

[2] C. P. Antodi, A. B. Prasetijo, and E. D. Widianto, "Penerapan Quality of Service pada Jaringan 
Internet Menggunakan Metode Hierarchical Token Bucket,” J. Teknol. dan Sist. Komput., vol. 5, no. 1 , p. 23, 2017.

[3] A. Al-Dulaimy, W. Itani, J. Taheri, and M. Shamseddine, "BWSLICER: A Bandwidth Slicing Framework for Cloud Data Centers," Futur. Gener. Comput. Syst., vol. 112, pp. 767-784, 2020.

[4] N. S. Hanum, "Keefetifan E-learning Sebagai Media Pembelajaran (Studi Evaluasi Model Pembelajaran E-learning SMK Telkom Sandhy Putra Purwokerto),” J. Pendidik. Vokasi, vol. 3, no. 1, pp. 90-102, 2013.

[5] I. G. I. Darmawan and M. T. Kurniawan, "Desain dan Analisis Best Practice Physical Security dan Logical Security pada Data Center Fakultas Rekayasa Industri Universitas Telkom Menggunakan Standar Tia-942 dan Open Enterprise Security Architecture Design and Analysis of Best Practice Physical Sec," e-Proc. Eng., vol. 2, no. 2, pp. 5576-5586, 2015.

[6] K. Shahzad, Z. Jianqiu, M. Hashim, M. Nazam, and L. Wang, "Impact of Using Information and Communication Technology and Renewable Energy on Health Expenditure: A Case Study from Pakistan," Energy, vol. 204, p. 117956, 2020.

[7] C. Abid, M. Kessentini, and H. Wang, "Early Prediction of Quality of Service Using InterfaceLevel Metrics, Code-Level Metrics, and Antipatterns," Inf. Softw. Technol., vol. 126, p. 106313, 2020.

[8] W. Li, U. Hommel, and S. Paterlini, "Network Topology and Systemic Risk: Evidence from The Euro Stoxx Market," Financ. Res. Lett., vol. 27, pp. 105-112, 2018.

[9] V. Gokhale, J. Nair, S. Chaudhuri, and J. Fesl, "On QoS-Compliant Telehaptic Communication Over Shared Networks,” Comput. Networks, vol. 165, 2019. 